\title{
Evaluation and comparison of three antimicrobial activity methods using bifidobacteria bifidum and bifidobacteria infantis as probiotic bacteria against salmonella enterica serotype enteritidis
}

\begin{abstract}
Background: Using the antimicrobial assays for determining the inhibitory effects of many compounds and also microorganisms has been ordinary in researching food and drug laboratories. During the last decades, the prevalence of foodborne diseases due to contaminated food as well as demand for natural and healthy foods has increased. Using probiotics for this purpose and for inhibiting growth of food pathogens is an interesting topic.

Objective: The aim of this study was to investigate three different methods namely spot on lawn assay, agar well diffusion assay(Cup plate assay) and agar disk diffusion assay and to compare the methods by the means of SPSS program for the antibacterial effects of Bifidobacterium bifidum and Bifidobacterium infantis against salmonella entericaserotype Enteritidis.
\end{abstract}

Material and methods: Supernatant and sediment of the two probiotic bacteria culture was tested in three different assays (spot-on-lawn, well diffusion and disk diffusion) against salmonella.

Results: In this study Well diffusion assay (Cup plate assay) was the best method to identify the antagonism of microorganisms and spot- on lawn method was the worse. Also in all three methods, the supernatant was significantly more effective than sediment in inhibiting the pathogen. Results showed that in all three assays, sediment and supernatant of Bifidobacterium infantis culture had a greater inhibition effect on salmonella than Bifidobacterium bifidum but the difference was not significant from statistical analyses point of view.

Discussion: Better functioning of Well diffusion assay (Cup plate method) could be explained by high accuracy and volume of supernatant used in this method. The inhibition zone in all three methods could be related to metabolites such as Acids, Diacetyle, Hydrogen proxide, Bacteriocins,... produced by probiotics.

Keywords: antibacterial effects methods, spot-on-lawn, well diffusion, disk diffusion background
Volume 2 Issue 3 - 2016

\author{
Nahid Rahimifard,' Mandana Moghni, ${ }^{2}$ mina \\ Naseri ${ }^{3}$ \\ 'Department of Microbiology, Food and Drug Control \\ Laboratories (FDCL), Iran \\ ${ }^{2}$ Sharecord University of medical sciences, Iran \\ ${ }^{3}$ Department of Microbiology, University of Islamic Azad, Iran
}

Correspondence: Nahid Rahimifard, Associate Professor in Microbiology, Doctorate in Medical Diagnostic Laboratory Sciences, Iran, Tel +989/21032806 Email nahidrahimifard@gmail.com

Received: April 12, 2016 | Published: July 13, 2016

\section{Introduction}

Bifidobacterium spices are one of the most abundant microbes in natural micro flora of colon. About $25 \%$ of adult stool bacteria and $80 \%$ of infant stool bacteria are Bifidobacterium. ${ }^{1}$ This bacterium is gram positive, rod shaped, immobile, non-spore forming, catalase negative and the major product of their metabolism is acetic and lactic

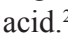

Bifidobacterium spices play an important role in human health by prevention of intestinal infections, decreasing cholesterol, stimulating immune system therefore decreasing cancer risks. ${ }^{3-5}$ Some of the spices in this genus are categorized as probiotics.

Probiotics is a word composed of two parts: the preposition pro (pro) with Latin origin and means "for" and biotic characteristics (biotic) with Greek origin and means "life". Probiotics have been defined for many, the first by Fuller (1992) and is defined as : A live microbial food supplements that are beneficial effect on the host by improving its intestinal microbial balance. ${ }^{5}$ This definition is still used today with slight change .Probiotics include several groups of bacteria, including lactic acid bacteria group that contains lactobacilli, Bifidobacterium, (Lactic acid bacteria are classified in the group but little phylogenetic similarity to other members of the group).

Some streptococci, Pedi cock and Lactococcus, and other species of lactic acid, are such as Propionibacterium acnes, Bacillus, and yeasts such as Saccharomyces ${ }^{5}$ Probiotics lactic and acetic acids, bacteriocin, hydrogen peroxide, di-acetyl, acetaldehyde and ammonia can have inhibitory effects on many microorganisms. Lactic acid and acetic fermentation of glucose and sucrose, organic acids by bacteria made and low $\mathrm{pH}$ conditions for the growth of undesirable bacteria are pathogens. Probiotics are bacteria that are common in many studies in vitro and in vivo, and its antagonist properties are shown by pathogenic bacteria. The studies are very valuable 
properties such as resistance to enteric pathogens, has been proposed treatment and prevention of bacterial and viral diarrhea and about probiotics. L. Gasseri anaerobic, gram-positive, rod-shaped, nonspore-inducing and one of the main species of lactobacilli inhabiting the gastrointestinal tract of humans and other animals. Materials such as organic acids, hydrogen peroxide, di-acetyl, antifungal compounds such as fatty acids and substances called bacteriocin that will prevent the growth of pathogenic microorganisms. Salmonella bacteria, Gram-negative, non-spore-forming anaerobic who are members of the Enterobacteriaceae family. Salmonella taken its name from pathologist about a century ago, these bacteria as a food pathogen in humans is very important and leads to Gastroenteritis in humans. Salmonella group into two subgroups, called Salmonella enterica and salmonella bongori split most virulent strains of subtypes are enterica. With more than 2511 serotypes of Salmonella, the second component can cause disease in America is caused by consumption of contaminated food. ${ }^{6}$

According to research studies and statistical information, products such as chicken, beef, pork, fish, milk, eggs are a source of transmission of these bacteria to human salmonellosis ${ }^{6}$ given the importance of salmonellosis and Salmonella in foods appears to be a mechanism to prevent such complications could be the use of probiotic bacteri. Therefore, the present study was to evaluate and compare the effects of antibacterial activity Bifidobacterium bifidum and Bifidobacterium infantis on Salmonella enterica serotype enteritidis.

Probiotics are a big group of bacteria consisting of lactic acid bacteria (like Lactobacillus, Bifidobacterium, some Streptococci, Pediococcus and Lactococci) and none lactic acid bacteria like Propionibacterium, Bacillus and some yeasts like saccharomyces. ${ }^{2}$

Many in vivo and in vitro experiments have shown the antagonistic effect of probiotics against many pathogens. Probiotics inhibit the growth of many microorganisms by producing lactic and acetic acid, bacteriocins, hydrogen peroxide, diacetyl, acetaldehyde and ammonia. $^{7-9}$ In these researches some really valuable characteristics like resistance to intestinal pathogens, prevention and curing of bacterial and viral diarrhea have been related to probiotics. ${ }^{10-13}$ Inhibition of salmonella spices by probiotics is a proof of their beneficial effect. ${ }^{4,14-16}$

\section{Objectives}

The aim of this study was to investigate the antibacterial effects of Bifidobacterium bifidum and Bifidobacterium infantis against salmonella enterica serotype Enteritidis by three different method namely spot on lawn assay, agar well diffusion assay and agar disk diffusion assay and to compare the accuracy of these methods by the means of SPSS program.

\section{Materials and methods}

\section{Preparing the probiotic and pathogen culture}

Lyophilized Bifidobacteria strains (Bifidobacterium bifidum Bbis 015 and Bifidobacterium infantis Bins 012) were obtained from Zist Takhmir Company and were anaerobically (with gas pack A) activated in MRS broth (Merck1.10661.0500) for 3-5days. Then the cultures were frozen in micro tubes containing $30 \%$ glycerol as cryoprotectant and held in $-80^{\circ} \mathrm{C}$ freezer. Before experimental tests, cultures were propagated overnight in broth media.
The pathogen used for antagonistic test was Salmonella enterica serotype Enteritidis ATCC 13311 which was obtained at lyophilized form and activated in TBS broth (Merck1.05459.0500) culture then the cultures were frozen in micro tubes containing 30\% glycerol and held at $-80^{\circ} \mathrm{C}$ freezer. Before experimental tests, culture was propagated overnight in broth media.

\section{Preparation of cell-free supernatants}

StrainsBifidobacterium bifidum Bbis 015 and Bifidobacterium infantis Bins 012 to be tested for antimicrobial activity were incubated in MRS broth(Merck1.10661.0500) for $48 \mathrm{~h}$ at $37^{\circ} \mathrm{C}$. Bacterial cells were removed by centrifuging the culture at $3500 \mathrm{~g}$ for $25 \mathrm{~min}$ at $4^{\circ} \mathrm{C}$. The supernatants were membrane filtered $(0.22 \mu \mathrm{m})$ and stored at $4^{\circ} \mathrm{C}$ in sterile conditions. The sediments also at $4^{\circ} \mathrm{C}$ in sterile conditions.

\section{Antimicrobial assay}

The assay was performed with three different methods:

i. Spot on lawn assay

ii. Agar well diffusion assay

iii. Agar disk diffusion assay

Spot on lawn testing was carried out on MRS agar (Merck1.10660.0500) and soft. Muller- Hinton Broth (QUELAB QB-65-8547 100G) layers. MRS agar (Merck1.10660.0500) as first layer was poured in sterile plates then plates were inoculated with approximately $\left(1.5^{*} 10^{8} \mathrm{CFU} / \mathrm{ml}\right)$ equal to $0.5 \mathrm{McF}$ arland turbidity of Salmonella enterica serotype Enteritidis ATCC 13311 inoculom as pathogen bacteria by a sterile swab. 2 microliter Spots of supernatant and sediments were put on this layer ( 3 replicates, a positive and a negative control) and then plates were incubated for a short while( 15 minutes at $37^{\circ} \mathrm{C}$. Second layer consisting of soft Muller- Hinton Broth (QUELAB QB-65-8547 100G) (0.7\% agar and 2\% glycerol) was poured and plates were incubated for 3-5days in anaerobe conditions at $37^{\circ} \mathrm{C}$. The clear zone around spots then was recorded. Gentamicin was used as positive control and deionized water as negative control.

Agar well diffusion assay was carried out on Muller-Hinto agar. Muller- Hinton agar (Merck1.05437.0500) was poured in sterile plates and plate's surfaces were inoculated with pathogen. Wells were cut on plate by sterile pipet (with an approximate distance of $19 \mathrm{~mm}$ so that zones did not collide). Wells were filled by supernatant or sediment and incubated $3-5$ days at $37^{\circ} \mathrm{C}$ with closed lid and anaerobe conditions. The clear zone around spots then was recorded. ${ }^{17,18}$

Agar disk diffusion assay was carried out on Muller-Hinton agar by Kirby-Bauer disk diffusion susceptibility test protocol. Muller- Hinton agar was poured in sterile plates and plate's surfaces were inoculated with approximately $\left(1.5^{*} 10^{8} \mathrm{CFU} / \mathrm{ml}\right)$ equal to 0.5 McFarland turbidity of Salmonella enterica serotype Enteritidis ATCC 13311 inoculom as pathogen bacteria by a sterile swab. The inoculom optical density (OD) had been adjusted between $0.08-0.13$ in $620 \mathrm{~nm}$ in spectrophotometer. Standard blank disk with $6.4 \mathrm{~mm}$ diameter were put on plate (with an approximate distance of $19 \mathrm{~mm}$ so that zones did not collide. The disks were wetted by supernatant or sediment and incubated $3-5$ days at $37^{\circ} \mathrm{C}$ with closed lid and anaerobe conditions. The clear zone around spots then was recorded. ${ }^{17,18}$ 


\section{Results}

Table 1 displays total cell count of Muller-Hinton agar plates cultured with this diluted pathogen. This test was done to evaluate the approximate $\mathrm{CFU} / \mathrm{ml}$ of pathogen which is inhibited by probiotic bacteria (Table 1).

\section{Assaying inhibitory effect of both Bifidobacteria}

Results of studying the effect of Bifidobacteria supernatants on growth of Salmonella Enteritidisare presentedin (Figure 1). As it's shown both strains had inhibitory effect and a clear zone was formed around the spot, well or disk with the inhibition zone ranging from 2 to $16 \mathrm{~mm}$ (with considering Disk diameter $6.4 \mathrm{~mm}$ in disc diffusion assay). These results complied with. ${ }^{19-21}$

Table I Total count of salmonella in plates gathered of two dilutions and 3 replication of each

\begin{tabular}{|c|c|c|c|c|c|c|c|}
\hline \multirow{2}{*}{ Pathogen name } & \multicolumn{3}{|c|}{ Colonies counted at $\mathbf{1 0 - 5}$ dilution } & \multicolumn{3}{|c|}{ Colonies counted at 10-6 dilution } & \multirow{2}{*}{ Calculated CFU/ml } \\
\hline & Rep.1 & Rep.2 & Rep.3 & Rep.1 & Rep.2 & Rep.3 & \\
\hline S. enterica serotype Enteritidis & 167 & 186 & 156 & 80 & 33 & 62 & $7.49 \times 10^{5}$ \\
\hline
\end{tabular}

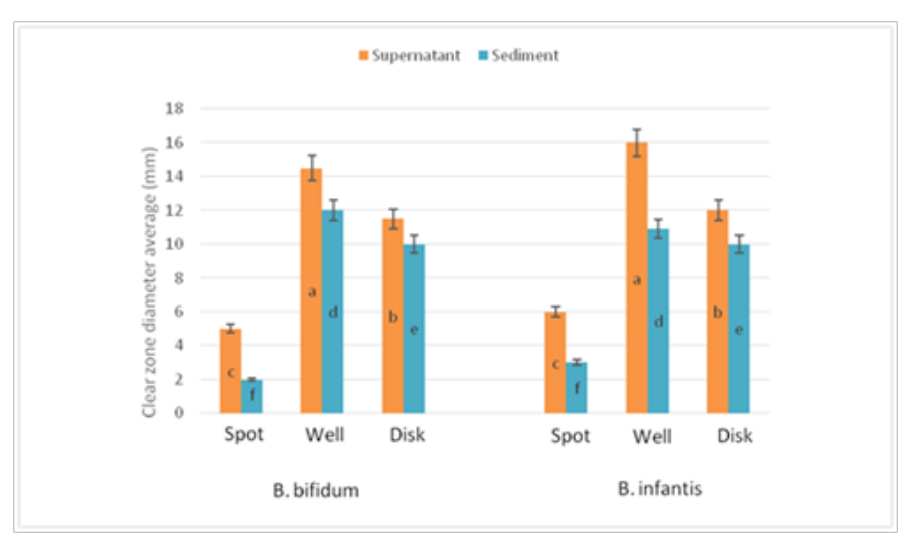

Figure I Inhibitory effect of Bifidobacterium bifidum and Bifidobacterium infantis (supernatant and culture sediment) against Salmonella in 3 different assays.

\section{Discussion}

Bifidobacteria are one of the most important groups of microorganisms to mankind being involved in prevention of intestinal infections, decreasing cholesterol, stimulating immune system therefore decreasing cancer risks. ${ }^{2-4}$ With every day passing a new aspect of probiotics is discovered and a new use is defined for them. One of these new aspect is the antagonism between Bifidobacteria and pathogens and it is related to the various compounds such as organic acids, diacetyl, hydrogen peroxide and bacteriocins produced by these microorganisms. ${ }^{7-9}$

Salmonella is a very important bacterium in food borne pathogens. This pathogen exists in food stuffs and plays a main role in food microbiology. ${ }^{22}$ During this study it was concluded that Bifidobacterium bifidum and Bifidobacterium infantis both had inhibitory effect against Salmonella Enteritidis, the infantis strain was slightly more effective but the difference was not statically significant. Makras et al., ${ }^{21}$ stated that Bifidobacterium bifidum had inhibitory effect against Salmonella Enteritidis and the reason is acid production and lowered $\mathrm{pH}$ which seems true since bacteriocins of Gram positive bacteria like Bifidobacteria is less effective against Gram negative bacteria such as Salmonella spices. ${ }^{21}$

The microbial quality of poultry paste as raw material, cooked and raw meats study show that microbial contamination especially Salmonella contamination in these food stuffs, and necessity for preventing ways of contamination. ${ }^{23}$

Gibson et al., ${ }^{20}$ investigated the regulatory effect of Bifidobacteria in intestine and decided that Bifidobacteria are of the most numerically important bacteria in intestine and maintain their host's health by some biological activities. One of these actions is inhibiting pathogens by producing acidic compounds like lactate and acetate. They also discovered that 8 strains of Bifidobacteria were able to produce antimicrobials with a large range of inhibitory and inhibit pathogens ike Salmonella, Listeria, campylobacter, Shigella and vibrio spices. ${ }^{21}$ Researches about inhibitory effect of Bifidobacterium infantis were rare.

Comparing the three methods used in this research, all 3 showed the antagonism between bacteria but the data obtained from them was different and this difference was statistically significant. Well diffusion assay was best to show this antagonism, then was disk diffusion assay and last was Spot on lawn assay. It could be as a result of high accuracy and high volume of supernatant used in well diffusion method. The spot method is a difficult and needs more proficiency also supernatant used in this method is less.

The result from comparison of assays was in contrast with 
the results obtained by Cadirci \& Citak et al., ${ }^{24}$ who investigated antagonism of LAB against Gram negative bacteria with two methods namely Spot on lawn assay and well diffusion assay and concluded that spot method was best for evaluation of LAB inhibitory effect. ${ }^{24}$

Antimicrobial Activity of Lactobacillus gasseri as Probiotic Bacteria against Salmonella EntericaSerotype Entertidis had been reported at 2015 by Moulood et al. ${ }^{25}$ Investigating the antibacterial effectiveness of Lactobacillus plantarum on Salmonella Entrica serotype entritidis had been reported at 2015 by Moulood Barzavar et al. ${ }^{26}$ In these studies result of comparing between antimicrobial methods have been the same obtaining from our study.

When comparing the inhibitory effect of Supernatant to sediment of cell culture, supernatant was significantly more effective and this was described as a result of better infusion of supernatant into soft agar, gathering of produced antimicrobial compounds in supernatant or damage to culture cells during centrifuging and therefore cell death.

\section{Acknowledgements}

The author sincerely thanks the Sarv Saadat Laboratory complexes in West sarv, Saadat abad, Tehran for their kind assistant and hard efforts.

\section{Conflict of interest}

The author declares no conflict of interest.

\section{References}

1. Picard C, Fioramonti J, Francois A, et al. Review article: bifidobacteria as probiotic agents - physiological effects and clinical benefits. Aliment Pharmacol Ther. 2005;22(6):495-512.

2. Charalampopoulos, Dimitris, Rastall, et al. Prebiotics and probiotics science and technology. USA: Springer; 2009.

3. Henriksson A, Conway PL. Isolation of human faecal bifidobacteria which reduce signs of Salmonella infection when orogastrically dosed to mice. $J$ Appl Microbiol. 2001;90(2):223-228.

4. Huebner ES, Surawicz CM. Probiotics in the prevention and treatment of gastrointestinal infections. Gastroenterol Clin North Am. 2006;35(2):355365

5. Foley SL, Lynne AM. Food animal-associated Salmonella challenges: pathogenicity and antimicrobial resistance. J Anim Sci. 2008;86(14 suppl):E173-E187.

6. Saroj SD, Shashidhar R, Karani M, et al. Rapid, sensitive, and validated method for detection of Salmonella in food by an enrichment broth cultureNested PCR combination assay. Mol Cell Probes. 2008;22(3):201-206.

7. Abdelbasset M, Djamila K. Antimicrobial activity of autochthonous lactic acid bacteria isolated from Algerian traditional fermented milk "Raïb". African Journal of Biotechnology. 2008:7(16).

8. Bromberg R, Moreno I, Zaganini CL, et al. Isolation of bacteriocinproducing lactic acid bacteria from meat and meat products and its spectrum of inhibitory activity. Braz J Microbiol. 2004;35(1-2):137-144.

9. Oyetayo V, Adetuyi F, Akinyosoye F. Safety and protective effect of Lactobacillus acidophilus and Lactobacillus casei used as probiotic agent in vivo. African Journal of Biotechnology. 2004;2(11):448-452.
10. Biller J, Katz A, Flores A, et al. Treatment of recurrent Clostridium difficile colitis with Lactobacillus GG. J Pediatr Gastroenterol Nutr. 1995;21(2):224-226.

11. Elmer GW. Probiotics:" living drugs". Am J Health Syst Pharm. 2001;58(12):1101-1109.

12. Maragkoudakis PA, Zoumpopoulou G, Miaris C, et al. Probiotic potential of Lactobacillus strains isolated from dairy products. International Dairy Journal. 2006;16(3):189-199.

13. Saavedra J. Probiotics and infectious diarrhea. Am J Gastroenterol. 2000;95(1 Suppl):S16-S18.

14. Miller HJM, Gibson GR, Bruck W. Some insights into the derivation and early uses of the word 'probiotic'. Br J Nutr. 2003;90(4):845-845.

15. Isolauri E, Kirjavainen P, Salminen S. Probiotics: a role in the treatment of intestinal infection and inflammation? Gut. 2002;50(3):54-59.

16. Lewis SJ, Freedman AR. Review article: the use of biotherapeutic agents in the prevention and treatment of gastrointestinal disease. Aliment Pharmacol Ther. 1998;12(9):807-822.

17. Darsanaki RK, Rokhi ML, Aliabadi MA, et al. Antimicrobial activities of Lactobacillus strains isolated from fresh vegetables. Middle-east journal of scientific research. 2012;11(9):1216-1219.

18. Hajimehdipoor H, Samadi N, Mozaffarian V, et al. Chemical composition and antimicrobial activity of Oliveria decumbens volatile oil from west of Iran. Journal of Medicinal Plants. 2010;9(6):39-44.

19. Bielecka $\mathrm{M}$, Biedrzycka $\mathrm{E}$, Biedrzycka $\mathrm{E}$, et al. Interaction of Bifidobacterium and Salmonella during associated growth. Int J Food Microbiol. 1998;45(2):151-155.

20. Gibson G, Wang X. Regulatory effects of bifidobacteria on the growth of other colonic bacteria. Journal of Applied Bacteriology. 1994;77(4):412420 .

21. Makras L, De Vuyst L. The in vitro inhibition of Gram-negative pathogenic bacteria by bifidobacteria is caused by the production of organic acids. International Dairy Journal. 2006;16(9):1049-1057.

22. Rahimifard N, Shoeibi SH, Hamedani MP, et al. The presence and control of Salmonella in food stuffs . Biosciences Biotechnology Research Asia. 2008;5(2):647-649.

23. Rahimifard N, Shoeibi SH, Hamedani MP, et al. The microbial quality of poultry paste as raw material, cooked and raw meats in Iran. Journal of Pure and Applied Microbiology. 2009;3(1):91-93.

24. Cadirci BH, Citak S. A Comparison of Two Methods Used for Measuring Antagonistic Activity of Lactic Acid Bacteria. Pakistan Journal of Nutrition. 2005;4(4):237-241.

25. Moulood B, Nahid R. ntimicrobial Activity of Lactobacillus gasseri as Probiotic Bacteria Against Salmonella Enterica Sero type Entertidis. GMP Review. 2015;16(4):56-64.

26. Moulood B, Nahid R. Investigating the antibacterial effectiveness of Lactobacillus plantarum on Salmonella Entrica serotype entritidis. Acta Cirurgica Brasileria. 2015;5. 